\title{
Editorial: Advances in the Evolutionary Ecology of Termites
}

\author{
Alberto Arab ${ }^{1}$, Solange Issa ${ }^{2}$ and Daniel Aguilera-Olivares ${ }^{3 *}$ \\ ${ }^{1}$ Centro de Ciências Naturais e Humanas, Universidade Federal do ABC (UFABC), Santo André, Brazil, ${ }^{2}$ Laboratorio de \\ Comportamiento y Manejo de Plagas, Departamento de Biología de Organismos, Universidad Simón Bolívar, Caracas, \\ Venezuela, ${ }^{3}$ Laboratorio de Entomología Forestal, Departamento de Silvicultura, Facultad de Ciencias Forestales, \\ Universidad de Concepción, Concepción, Chile
}

Keywords: eusociality, Blattodea, nest, task allocation, symbiosis, ecosystem engineers

\section{Editorial on the Research Topic}

\section{Advances in the Evolutionary Ecology of Termites}

Termitology has seen great advances in research during the last decades accompanied by an increasing number of scientists and research centers, which is reflected in the growing number of scientists attending meetings (Chouvenc et al., 2018) and published articles. Although ants and bees have been the most prominently researched social insects in general over the last 45 years (Figure 1A), termites have been the most researched social insects regarding the topics of ecology and evolution (Figure 1B). Thus, in this Research Topic the growing interest in evolutionary ecology of termite research is summarized in six original research articles and two reviews, providing updated information on diverse aspects of the biogeography, evolutionary biology, genomics, systematics, microbiology and chemical ecology of these fascinating insects.

Termites (Blattodea: Isoptera) are eusocial insects that live in colonies containing hundreds

\section{OPEN ACCESS}

Edited and reviewed by:

Elise Huchard

UMR5554 Institut des Sciences de l'Evolution de Montpellier (ISEM), France

${ }^{*}$ Correspondence:

Daniel Aguilera-Olivares daguilera@udec.cl

Specialty section

This article was submitted to Behavioral and Evolutionary Ecology,

a section of the journal

Frontiers in Ecology and Evolution

Received: 22 April 2021 Accepted: 31 May 2021

Published: 24 June 2021

Citation:

Arab A, Issa S and Aguilera-Olivares D (2021) Editorial: Advances in the Evolutionary Ecology of Termites.

Front. Ecol. Evol. 9:698937.

doi: 10.3389/fevo.2021.698937 to millions of individuals organized into reproductive and non-reproductive castes with specific tasks such as nest construction, foraging, reproduction, brood care, and colony defense (Korb and Hartfelder, 2008). They comprise over 3,000 species distributed in nine families sharing a common ancestor with wood feeding cockroaches of the genus Cryptocercus (Krishna et al., 2013; Bourguignon et al., 2015), and are thus considered eusocial cockroaches. Termites have gained the ability to digest lignocellulose through obligate symbiosis, leading to other major adaptations: alloparental care, trophallaxis, and the emergence of sterile castes; all together allowed the evolution of eusociality, the most complex level of social organization, for the first time in the history of the Earth about 150 Mya (Korb et al., 2012; Bourguignon et al., 2015; Chouvenc et al., 2021).

Traditionally, termites have been classified into "lower" and "higher" termites. "Lower" termites (all termite families except Termitidae) consist typically of wood-feeding species that depend mainly on flagellate protists for lignocellulose digestion (Engel et al., 2009). On the other hand, "higher" termites (Termitidae) are the most numerous, diverse and successful group of termites. Their evolutionary success is attributed to their symbiotic association with gut microorganisms (Ohkuma et al., 2009; Dietrich et al., 2014), mainly to the loss of flagellates and the acquisition of specialized bacteria with a high repertoire of lignocellulases, accompanied by a dietary diversification (Bignell and Eggleton, 2000; Brune, 2014). The food sources of "higher" termite lineages include wood, grasses, litter, micro-epiphytes, the mycelia of symbiotic fungi, organic soil and even inorganic soil (Donovan et al., 2001; Eggleton and Tayasu, 2001).

A major topic in termite ecology is the effect of habitat degradation on the diversity of these insects, especially in highly threatened biomes (Bullock et al., 2020). The impact of soil degradation on termite assemblages is investigated in this Research Topic by Duran-Bautista et al. at different land use systems in the Amazon. Local environmental factors such as vegetation type, rainfall, 


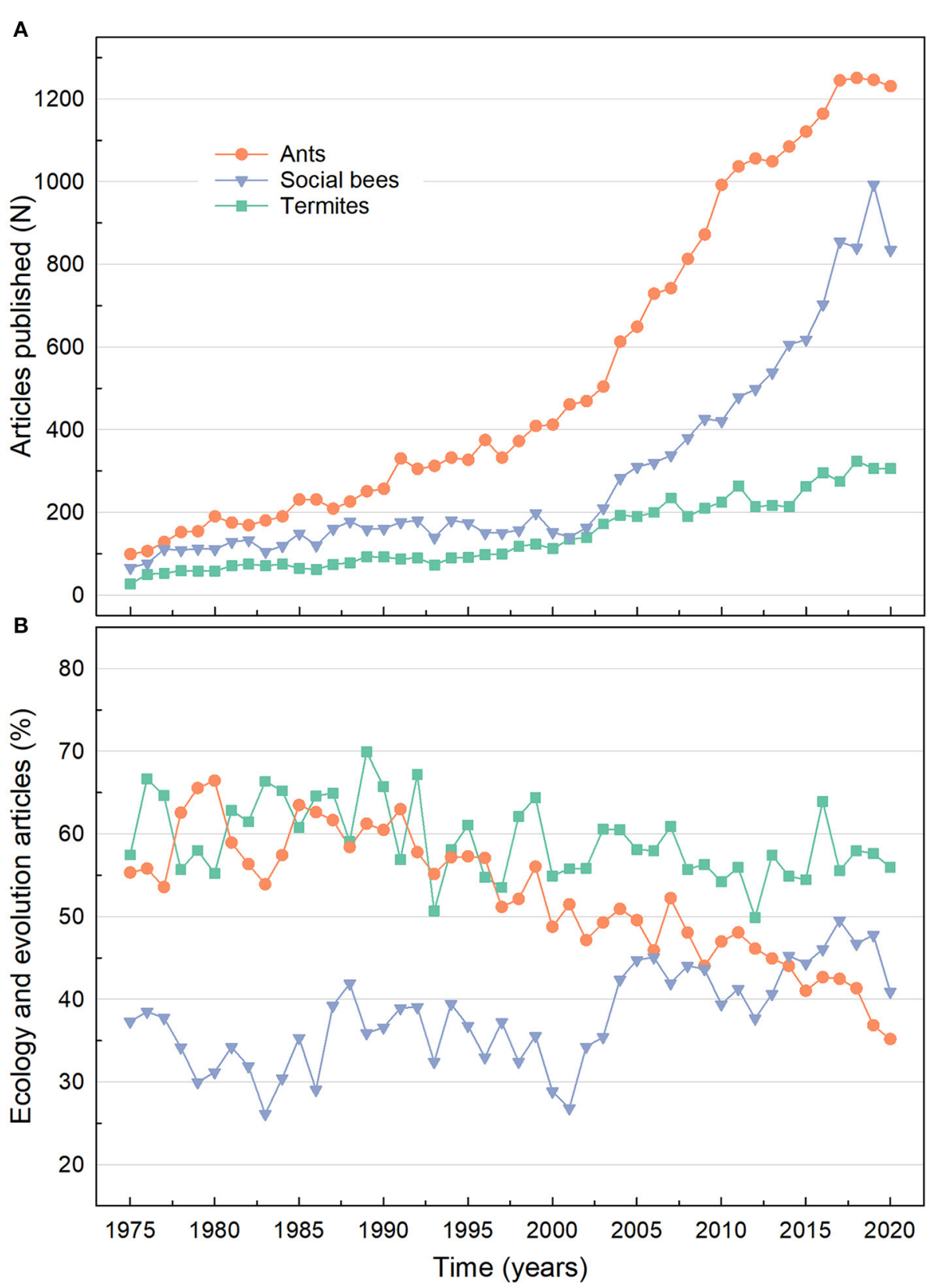

FIGURE 1 | Articles published for ants, social bees, and termites from 1975 to 2020 in all databases available on ISI Web of Knowledge. (A) Number of articles published by year for ants (keyword search: "ants"); social bees (keyword search: "orchid bees OR bumble bees OR stingless bees OR honey bees"), and termites (keyword search: "termites"). (B) Percentage of articles published by year on ecology or evolution topic for ants [keyword search: "ants AND (ecology OR evolution)"], social bees [keyword search: "(orchid bees OR bumble bees OR stingless bees OR honey bees) AND (ecology OR evolution)"], and termites [keyword search: "termites AND (ecology OR evolution)"].

elevation and latitude, are also known to differentially affect termite diversity. In their Original Research Article, Clement et al. address the question of how vegetation type and rainfall affect termite assemblages by evaluating guilds, activity and diversity of these insects in several Australian biomes.

Molecular analyses and biochemical activity are useful tools to uncover the complexity of the ecological and evolutionary dynamics of termite-symbiont association. "Lower" termites, depend on several lineages of flagellate protists for food digestion (Engel et al., 2009), and because protists are inherited vertically from the parents their distribution seems to be determined by host phylogeny (Tai et al., 2015). In their Original Research, De Martini et al. discuss the drivers of protist diversification in the context of host genetic relationship. Furthermore, the digestion of plant tissues is driven by mutualistic ectosymbiosis in fungus-growing termites (Macrotermitinae), which is considered 
an evolutionary novelty in "higher" termites originated about 30 Mya after the acquisition of gut symbionts by the ancestor of Termitidae (Aanen et al., 2002; Bourguignon et al., 2015; Bucek et al., 2019; Chouvenc et al., 2021). In this context, Korb et al. provide new evidence about the transmission of Termitomyces to their siblings in fungus-growing termites by evaluating whether the mode of transmission is related to the ecological success of these termites in West Africa. Finally, Moreira et al. investigated the role of nest bacteria and fungi in a food storing Syntermitinae through a combination of microbiome, genomics and transcriptomics. Mounds of these termites are made of soil and feces, and could function as a prefermentation chamber for the plant biomass that is stored in fecal made nodules (Menezes et al., 2018). This study showed the role of nest microbiota as a complementary system for lignocellulose digestion in the context of higher termite evolution.

Caste differentiation pathways in termites are regulated by complex postembryonic mechanisms. In this Research Topic, Oguchi et al., reviewed the differentiation pathways underlying the developmental mechanisms and evolutionary origin of the caste of neotenics, which act as secondary or replacement reproductives and constitute a termite synapomorphy. Lastly, Lee et al. investigated how hybridization between phylogenetically closed pest termite species affect the activity of sterile castes. The role of pheromones in communication and physiological regulation in termites from an evolutionary point of view is reviewed in this Research Topic by Mitaka and Akino.

In conclusion, our Research Topic highlight the latest advances in termite evolutionary ecology and cover a wide

\section{REFERENCES}

Aanen, D. K., Eggleton, P., Rouland-Lefevre, C., Guldberg-Froslev, T., Rosendahl, S., and Boomsma, J. J. (2002). The evolution of fungus-growing termites and their mutualistic fungal symbionts. Proc. Natl. Acad. Sci. U.S.A. 99, 14887-14892. doi: 10.1073/pnas.222313099

Bignell, D. E., and Eggleton, P. (2000). "Termites in ecosystems," in Termites: Evolution, Sociality, Symbioses, Ecology, eds T. Abe, D. E. Bignell, and M. Higashi (Dordrecht: Springer). doi: 10.1007/978-94-017-3223-9_17

Bourguignon, T., Lo, N., Cameron, S. L., Šobotník, J., and Hayashi, Y., Shigenobu, S., et al. (2015). The evolutionary history of termites as inferred from 66 mitochondrial genomes. Mol. Biol. Evol. 32, 406-421. doi: 10.1093/molbev/msu308

Brune, A. (2014). Symbiotic digestion of lignocellulose in termite guts. Nat. Rev. Microbiol. 12, 168-180. doi: 10.1038/nrmicro 3182

Bucek, A., Šobotník, J., He, S., Shi, M., and McMahon, D. P., Holmes, E. C., et al. (2019). Evolution of termite symbiosis informed by transcriptomebased phylogenies. Curr. Biol. 29, 3728-3734.e4. doi: 10.1016/j.cub.2019. 08.076

Bullock, E. L., Woodcock, C. E., Souza, C., and Olofsson, P. (2020). Satellite-based estimates reveal widespread forest degradation in the Amazon. Glob. Chang. Biol. 26, 2956-2969. doi: 10.1111/gcb.15029

Chouvenc, T., Li, H.-F., and Su, N.-Y. (2018). Connecting Termite Researchers from Around the World at ICE 2016. Am. Entomol. 64, 152-154. doi: 10.1093/ae/tmy051

Chouvenc, T., Šobotník, J., Engel, M. S., and Bourguignon, T. (2021). Termite evolution: mutualistic associations, key innovations, and the rise of Termitidae. Cell. Mol. Life Sci. 1, 3. doi: 10.1007/s00018-02003728-z range of research areas: evolutionary biology, genomics, systematics, microbiology, biogeography, and ethology in 90 termite species, showing the increasing interest of researchers from around the world to study these amazing insects. This knowledge is expected to continue growing during the next years and have an impact into the development of new biotechnological applications such as: biodegradation, development of antibiotics and antifungal, biofuels and pest control industry.

\section{AUTHOR CONTRIBUTIONS}

All authors listed have made a substantial, direct and intellectual contribution to the work, and approved it for publication.

\section{FUNDING}

Research of Topic Editors is supported by the São Paulo Research Foundation (FAPESP), grants \# 2015/21497-6 and 2018/228396 to AA, and FONDECYT postdoctoral project $\mathrm{N}^{\circ} 3190381$ to $\mathrm{DA}-\mathrm{O}$.

\section{ACKNOWLEDGMENTS}

We are very grateful to all the authors for their contribution to this Research Topic illustrating several directions on termite research. We also thank all reviewers and the Frontiers Editorial team for the invaluable support. We are grateful to Tiago Carrijo for providing pictures and Johana Rincones for useful comments.

Dietrich, C., Köhler, T., and Brune, A. (2014). The cockroach origin of the termite gut microbiota: patterns in bacterial community structure reflect major evolutionary events. Appl Env. Microbiol. 80:13. doi: 10.1128/AEM.04206-13

Donovan, S. E., Eggleton, P., and Bignell, D. E. (2001). Gut content analysis and a new feeding group classification of termites. Ecol. Entomol. 26, 356-366. doi: 10.1046/j.1365-2311.2001.00342.x

Eggleton, P., and Tayasu, I. (2001). Feeding groups, lifetypes and the global ecology of termites. Ecol. Res. 16, 941-960. doi: 10.1046/j.1440-1703.2001.00444.x

Engel, M. S., Grimaldi, D. A., and Krishna, K. (2009). Termites (Isoptera): their phylogeny, classification, and rise to ecological dominance. Am. Museum Novit. 3650, 1-27. doi: 10.1206/651.1

Korb, J., Buschmann, M., Schafberg, S., Liebig, J., and Bagnères, A.-G. (2012). Brood care and social evolution in termites. Proc. R. Soc. B Biol. Sci. 279, 2662-2671. doi: 10.1098/rspb.2011.2639

Korb, J., and Hartfelder, K. (2008). Life history and development - a framework for understanding developmental plasticity in lower termites. Biol. Rev. 83, 295-313. doi: 10.1111/j.1469-185X.2008.00044.x

Krishna, K., Grimaldi, D. A., Krishna, V., and Engel, M. S. (2013). Treatise on the Isoptera of the world. Bull. Am. Museum Nat. Hist. 1, 1-2704. doi: $10.1206 / 377.1$

Menezes, L., Alvarez, T. M., Persinoti, G. F., Franco, J. P., Squina, F., Moreira, E. A., et al. (2018). Food storage by the savanna termite cornitermes cumulans (syntermitinae): a strategy to improve hemicellulose digestibility? Microb. Ecol. 76, 492-505. doi: 10.1007/s00248-017-1128-2

Ohkuma, M., Noda, S., Hongoh, Y., Nalepa, C., a, and Inoue, T. (2009). Inheritance and diversification of symbiotic trichonymphid flagellates from a common ancestor of termites and the cockroach Cryptocercus. Proc. R. Soc. London B Biol. Sci. 276, 239-245. doi: 10.1098/rspb.2008.1094

Tai, V., James, E. R., Nalep, C. A., Scheffrahn, R. H., Perlman, S. J., and Keelinga, P. J. (2015). The role of host phylogeny varies 
in shaping microbial diversity in the hindguts of lower termites. Appl. Environ. Microbiol. 81, 1059-1070. doi: 10.1128/AEM.02 945-14

Conflict of Interest: The authors declare that the research was conducted in the absence of any commercial or financial relationships that could be construed as a potential conflict of interest.
Copyright $\odot 2021$ Arab, Issa and Aguilera-Olivares. This is an open-access article distributed under the terms of the Creative Commons Attribution License (CC BY).

The use, distribution or reproduction in other forums is permitted, provided the original author(s) and the copyright owner(s) are credited and that the original publication in this journal is cited, in accordance with accepted academic practice. No use, distribution or reproduction is permitted which does not comply with these terms. 